\title{
KOMPOSISI, KEPADATAN DAN KEANEKARAGAMAN JENIS GASTROPODA DI KAWASAN MANGROVE PESISIR PANTAI KAMBAPI PADA MUSIM PERALIHAN I
}

\author{
Modesta R. Maturbongs*, Sisca Elviana* \\ Staf Jurusan MSP, Faperta UNIMUS-Merauke,e-mail: modest_ranny@yahoo.co.id
}

\begin{abstract}
ABSTRAK
Penelitian ini bertujuan untuk mengetahui komposisi, kepadatan dan keanekaragaman jenis gastropoda yang hadir di kawasan mangrove pesisir Pantai Kembapi. Metode pengambilan sampel menggunakan garis transek tetap yang dikombinasikan dengan kuadran $1 \times 1 \mathrm{~m}^{2}$. Analisis data menggunakan beberapa indeks ekologi yaitu kepadatan jenis gastropoda, indeks keanekaragaman Shannon-Wiener, indeks kekayaan jenis Margalef dan indeks dominansi Simpson. Dari hasil penelitian diperoleh 10 spesies gastropoda yang tergolong dalam 3 sub-kelas, 5 ordo, 6 famili dan 7 genus. Presentase kehadiran tertinggi selama musim peralihan I diperoleh dari jenis Terebralia sulcata sebesar $32,92 \%$. Kepadatan tetinggi juga diperoleh dari jenis Terebralia sulcata sebesar $46,2 \mathrm{ind} / \mathrm{m}^{2}$ dan nilai kepadatan terendah diperoleh dari jenis Thais kieneri sebesar $0,4 \mathrm{ind} / \mathrm{m}^{2}$. Indeks keanekaragaman 1,922 tingkat keanekaragaman jenis gastropoda di lokasi penelitian pada kriteria sedang. Nilai indeks kekayaan jenis 1,087 dan nilai dominansi 0,179 dominansi dalam komunitas tersebut rendah dan menunjukkan struktur komunitas dalam keadaan stabil.
\end{abstract}

Kata Kunci: Komposisi, Kepadatan, Keanekaragaman, Gastropoda, Kambapi

\section{PENDAHULUAN}

1.1. Latar Belakang

Kawasan pesisir merupakan peralihan antara laut dan daratan yang masih dipengaruhi pasang surut, sedimentasi, aliran air tawar, dan aktifitas manusia (Pramudji, 2002). Salah satu biota yang terdapat pada kawasan pesisir adalah gastropoda, dimana keberadaannya sangat penting dalam menjaga keseimbangan ekologi wilayah pesisir (Tanjung, 2012). Gastropoda merupakan kelompok terbesar dan paling beragam dalam moluska, sekitar $\mathbf{5 0 . 0 0 0}$ spesies ditemukan (Yolanda et al.,2016). Kehadiran gastropoda di ekosistem mangrove sebagai bagian dari wilayah pesisir sangat dipengaruhi oleh kondisi pesisir itu sendiri (Tanjung, 2012).

Keberadaan gastropoda sangat penting dalam menjaga keseimbangan ekologi wilayah pesisir karena gastropoda salah satu dekomposer awal untuk pengurai serasah daun mangrove. Dilain pihak gastropoda juga merupakan sala satu kelas moluska yang memiliki nilai ekonomis penting bagi masyarakat pesisir. sebagai informasi awal tentang jenis dan komposisi gastropoda pada kawasan mangrove dengan tingkat kepadatannya berdasarkan musim. Penelitian ini bertujuan untuk melihat struktur komunitas gastropoda pada pesisir Kambapi Kabupaten Merauke. Penelitian ini bertujuan untuk mengetahui komposisi, kepadatan dan keanekaragaman jenis gastropoda pada musim peralihan I di kawasan mengrove pesisir Pantai Kambapi, Kabupaten Merauke.

\subsection{Tujuan Penelitian}

Penelitian ini bertujuan untuk mengetahui komposisi, kepadatan dan keanekaragaman jenis gastropoda pada musim peralihan I di kawasan mengrove pesisir Pantai Kambapi, Kabupaten Merauke. 


\section{METODE PENELITIAN}

Penelitian ini dilakukan pada kawasan mangreove pesisir Pantai Kambapi pada bulan April - Mei 2016. Peralatan yang digunakan dalam penelitian adalah GPS (Global Positioning System), transek tetap dari tali ๑ tambang, meteran roll, pipa paralon $1 \times 1 \mathrm{~m}^{2}$, 1 termometer, $\mathrm{pH}$ meter, handrefractometer, DOmeter, kamera digital, alat tulis, botol sampel, plastik sampel, dan kertas label. Sampel gastropoda diawatkan menggunakan alkohol $70 \%$ untuk identifikasi.

Pengambilan sampel gastropoda $\exists$ dilakukan pada saat air surut. Seluruh jenis gastropoda yang berada di akar, daun, batang mangrove yang berada dalam kuadran pengamatan dihitung dan diambil untuk dikoleksi. Sampel gastropoda yang dikoleksi, kemudian dicuci bersih dan dimasukkan dalam plastik sampel. Pengukuran parameter lingkungan dilakukan pada saat air pasang disetiap stasiun. Parameter perairan yang diambil berupa salinitas, suhu, oksigen terlarut dan $\mathrm{pH}$ air laut. Identifikasi jenis-jenis gastropoda yang ditemukan menggunakan beberapa literatur, yaitu Abbot (1982), Dance (1992), Jansen (2000), Dharma (1988) dan Dharma (1992), Woodward (1993).

Untuk mengetahui komposisi dan kepadatan dari gastropoda, maka digunakan beberapa formula indeks ekologi yaitu dengan mengukur kepadatan jenis gastropoda menurut
Brower dan Zar (1977). Indeks keanekaragaman Shannon-Wiener (1963), Kriteria keanekaragaman menurut Wilhm and Dorris, (1986) dalam Insafitri, (2010) terdapat 3 kategori, yaitu apabila $\mathrm{H}^{`}<1$ maka keanekaragaman jenis rendah, nilai $\mathbf{1}<\mathrm{H}^{\prime}<3$ maka keanekaragaman jenis sedang, dan apabila nilai $\mathrm{H}^{\prime}>3$ maka tingkat keanekaragaman jenis tinggi. Indeks kekayaan jenis gastropoda menggunakan formula indeks Margalef (Clifford \& Stephenson, 1975 dalam Khouw, 2009) dan indeks dominansi Simpson (1983). Nilai indeks dominansi berkisat antara 0-1, jika mendekati 0 berarti tidak ada individu yang mendominansi dan jika mendekati 1 berarti terdapat salah satu jenis yang mendominansi (Odum, 1971).

\section{HASIL DAN PEMBAHASAN}

\subsection{Karakteristik Habitat}

Pesisir Pantai Kambapi merupakan kawasan hutan mangrove yang memiliki kondisi yang masih baik walaupun daerah ini dahulunya merupakan daerah penggalian pasir. Suhu rata-rata perairan $29^{\circ} \mathrm{C}$, salinitas berkisar antara $26-29 \%$ dan $\mathrm{pH}$ perairan berkisar antara antara $7,5-8,1$. Secara umum lokasi penelitian memiliki jenis substrat lumpur berpasir. Jenis mangrove yang mendominansi lokasi penelitian yaitu Avicenia $s p$, serta beberapa jenis mangrove lain yaitu Rhizopora $s p$ dan Soneratia sp.

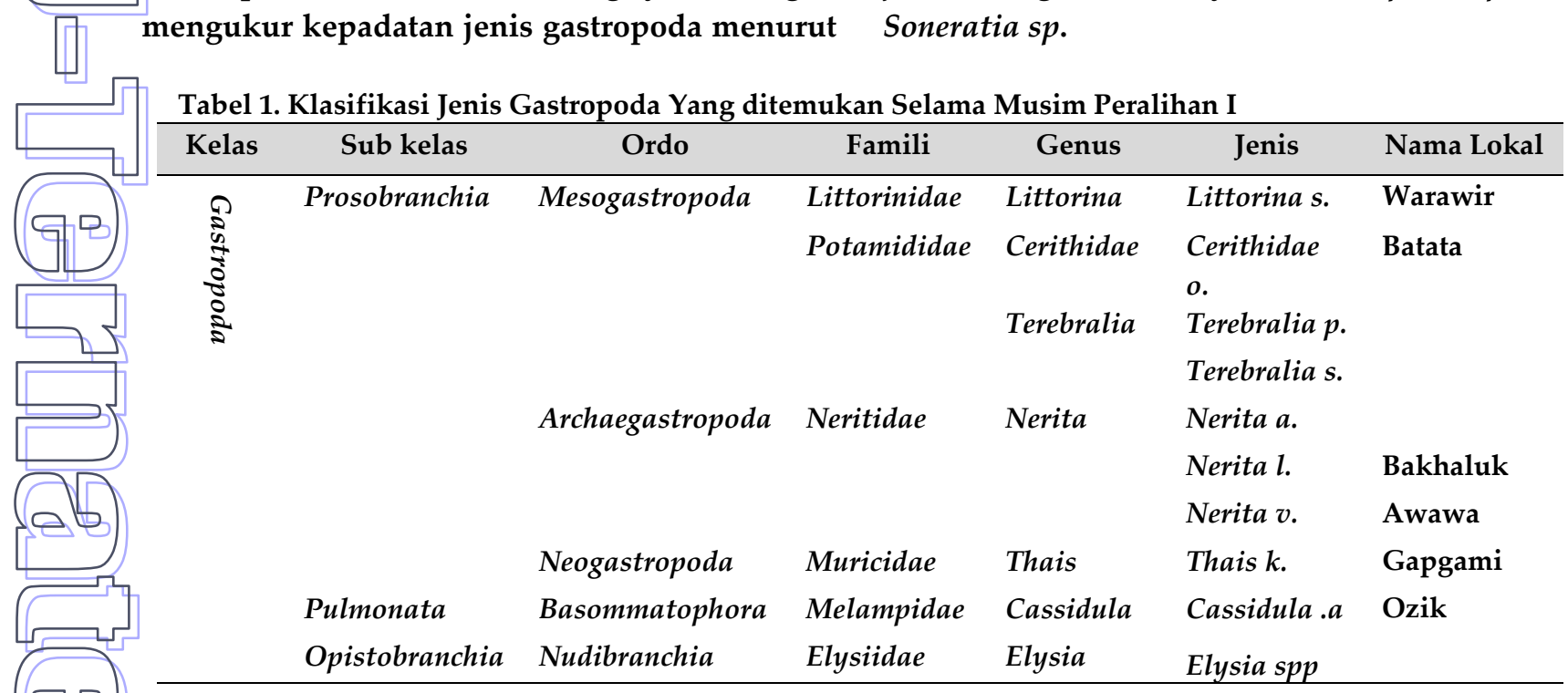

3.2. Komposisi dan Kepadatan Jenis

Hasil identifikasi gastropoda yang ditemukan pada lokasi penelitian diperoleh sebanyak 3928 individu, diperoleh 10 spesies gastropoda yaitu Littorina scabra, Cerithidae obtuse, Terebralia palustris, Terebralia 
palustris, Nerita Albicilla, Nerita lineata, Nerita violacea, Thais kieneri, Cassidula angulifera dan Elysia spp. Sembilan jenis gastropoda yang ditemukan tersebut tergolong dalam 3 sub-kelas, 5 ordo, 6 famili dan 7 genus (Tabel 1). Spesies yang mendominansi
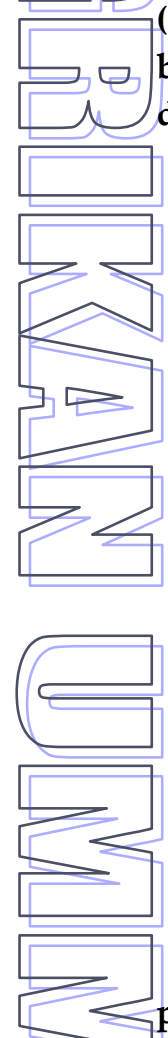

Dari hasil penelitian, famili Potamididae paling banyak ditemukan pada ekosistem mangrove hal ini sesuai dengan pernyataan Reksodihardjo et al. (1986) dalam Sujarno et al. (2013) menyatakan bahwa salah satu Gastropoda yang mendominasi areal mangrove adalah famili Potamididae.

Berdasarkan nilai indeks kepadatan diperoleh kepadatan jenis gastropoda selama Musim Peralihan I tertinggi dari ordo
Potamididae, jenis Terebralia sulcata sebesar $32,92 \%$, diikuti oleh family Littorinidae jenis Littorina scabra $12,27 \%$, dan jenis Elysia sp sebesar 11,35\% dari family Elysidae. Presentase jumlah individu terendah yang ditemukan pada transek diperoleh dari family Muricidae, Thais kieneri sebesar 0,25\% (Gambar 1).

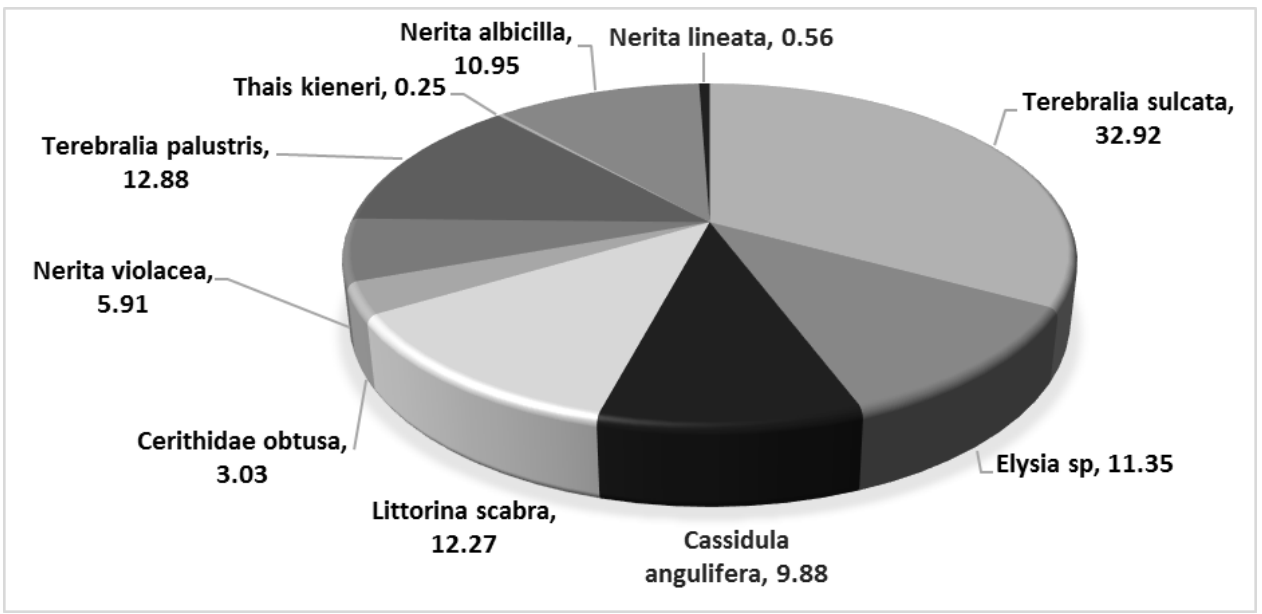

Gambar 1. Komposisi Jenis Gastropoda Selama Musum Peralihan I

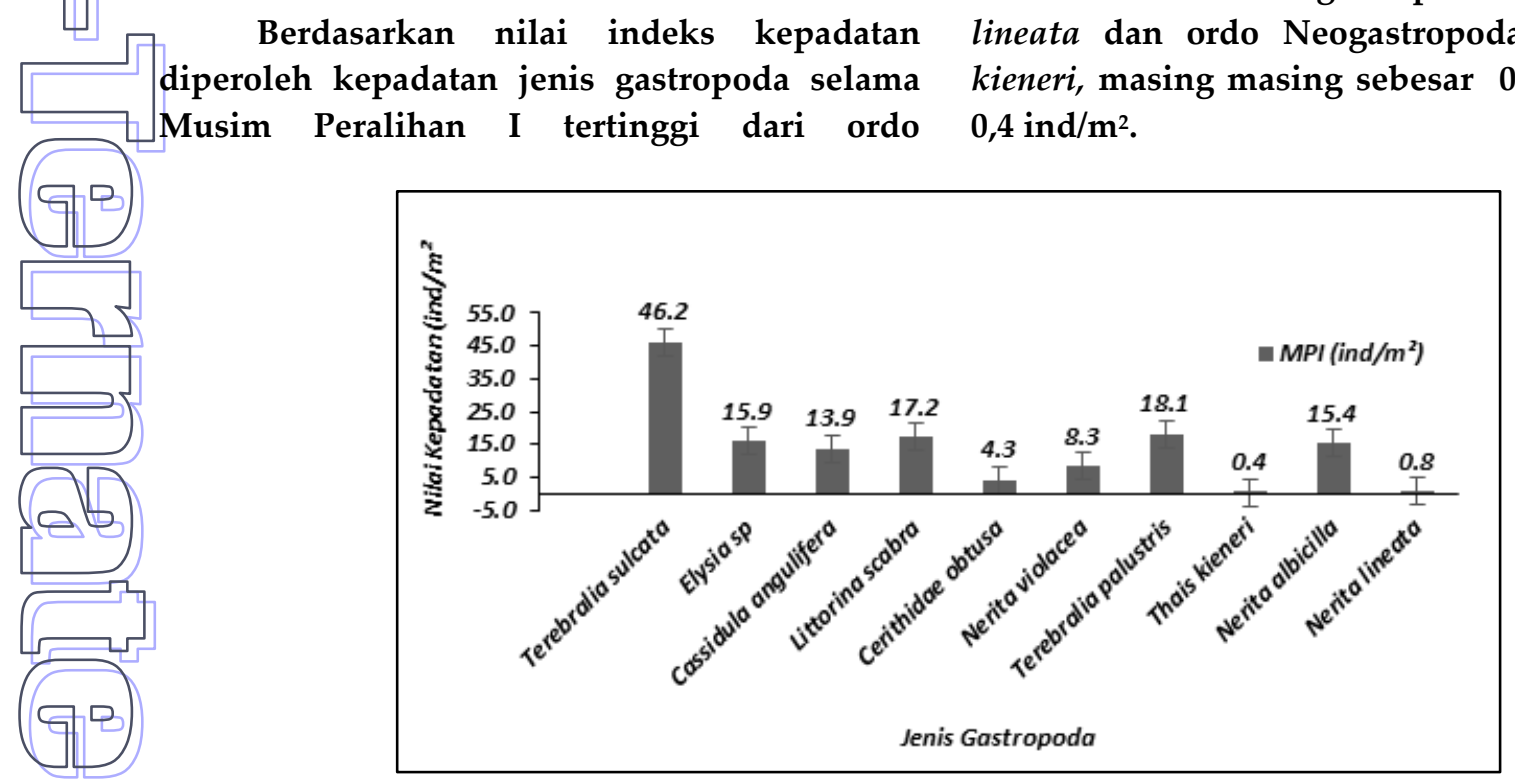

Gambar 2. Kepadatan Jenis Gastropoda Pada Musim Peralihan I 
Tingginya nilai kepadatan T. sulcata dikarenakan jenis gastropoda ini hidup dan berkembang di kawasan mangrove dalam jumlah besar terutama di sebagian besar jenis substrat berlumpur (Masagca et al.,2010). Hasil ini sesuai dengan penjelasan Dharma (1988) Q dan Budiman (1988) yang melaporkan bahwa hutan mangrove merupakan habitat yang paling disukai untuk famili Potamididae serta memiliki distribusi geografis yang luas dan juga ditemukan dalam kelimpahan yang tinggi di ekosistem mangrove. Odum (1998) juga menjelaskan bahwa suatu spesies dengan $\exists \unrhd$ kepadatan tertinggi menunjukkan bahwa organisme tersebut memiliki kemampuan menempati ruang yang lebih luas sehingga memiliki kemampuan berkembang lebih banyak.

3.3. Keanekaragaman, Kekayaan Jenis dan Dominansi Jenis Gastropoda
Hasil analisa indeks keanekaragaman jenis gastropoda pada ekosistem mangrove selama Musim Peralihan I (Tabel 2), berdasarkan kriteria keanekaragaman menurut Wilhm and Dorris, (1986) dalam Insafitri, (2010) menunjukkan tingkat keanekaragaman jenis gastropoda di lokasi penelitian pada kriteria sedang. Keanekaragaman jenis adalah ukuran sederhana dan berguna dari sistem biologi (Pravinkumar et al.,2013). Hal ini menunjukkan bahwa kondisi komunitas gastropoda pada ekosistem mangrove cukup seimbang dan tekanan ekologis sedang. Arbi (2012), menjelaskan tinggi rendahnya nilai indeks keanekaragaman jenis dapat disebabkan oleh jumlah jenis atau individu yang didapat kondisi substrat, kondisi ekosistem di wilayah pesisir. Penjelasan ini mendukung hasil penelitian dengan adanya beberapa jenis yang ditemukan dalam jumlah yang lebih melimpah daripada jenis lainnya.

Tabel 2. Indeks Ekologi Gastropoda Pada Musim Peralihan I

\begin{tabular}{cccc}
\hline \multirow{2}{*}{ Waktu } & \multicolumn{3}{c}{ Indek Ekologi Gastropoda } \\
& H'$^{\prime}$ & DMG & C \\
\hline Musim Peralihan I & 1.922 & 1.087 & 0.179 \\
\hline
\end{tabular}

Berdasarkan nilai kekayaan jenis gastropoda Rau $d k k$,(2013) menjelaskan nilai indeks kekayaan cenderung akan tinggi apabila suatu komunitas memiliki jumlah jenis yang banyak dan tiap jenis tersebut terwakili oleh satu individu, sebaliknya nilai indeks akan rendah jika komunitas memiliki jumlah jenis yang cenderung sedikit dan tiap jenis tersebut memiliki jumlah individu yang banyak. Pernyataan ini merujuk pada hasil indeks kekayaan jenis 1,087, hal ini menunjukkan kekayaan jenis gastropoda rendah. Pada komunitas gastropoda di ekosistem mangrove Pesisir Pantai Kambapi pada Musim Peralihan I terdiri dari 3928 individu yang terbagi dalam 10 jenis. Rendahnya nilai kekayaan jenis gastropoda disebabkan adanya masukan air tawar yang akibat hujan dan aliran air tawar dari kolam bekas galian pasir yang menurunkan kadar salinitas perairan di lokasi penelitian yang mempengaruhi distribusi dari organisme bentos. Hal ini sesuai dengan penelitian yang dilakukan oleh Pravinkumar et al.(2013) tentang biodiversitas bentos pada ekosistem mangrove.

Nilai dominansi Simpson gastropoda yang ditunjukkan pada Tabel 2 dan berdasarkan kisaran nilai indeks dominansi menurut Odum (1971), kurang dari 1 maka dominansi dalam komunitas tersebut rendah dan menunjukkan struktur komunitas dalam keadaan stabil. Macintosh et al (2002) menjelaskan bahwa dominasi tinggi satu spesies mungkin mengindikasikan lingkungan stres sementara keragaman yang lebih tinggi menunjukkan kondisi stabil dalam ekosistem.

\section{PENUTUP}

Jenis gastropoda pada Musim Peralihan I pada kawasan mangrove Pantai Kambapi diperoleh 10 spesies yang tergolong dalam 3 sub-kelas, 5 ordo, 6 famili dan 7 genus. Presentase kehadiran tertinggi selama musim ini diperoleh dari jenis Terebralia sulcata sebesar 32,92\%. Kepadatan tetinggi juga diperoleh dari jenis Terebralia sulcata sebesar $46,2 \mathrm{ind} / \mathrm{m}^{2}$ dan nilai kepadatan terendah 
diperoleh dari jenis Thais kieneri sebesar 0,4

ind $/ \mathrm{m}^{2}$. Indeks keanekaragaman 1,922 tingkat keanekaragaman jenis gastropoda di lokasi penelitian pada kriteria sedang. Nilai indeks kekayaan jenis 1,087 dan nilai dominansi 0,179 dominansi dalam komunitas tersebut rendah dan menunjukkan struktur komunitas dalam keadaan stabil.

\section{DAFTAR PUSTAKA}

Abbot R.T. \& Dance S.P., 1982. Compendium of Seashells. New York : E.P. Dutton, INC.

Arbi, U.Y.2012. Komunitas Moluska Di Padang Lamun Pantai Wori, Sulawesi Utara. Jurnal Bumi Lestari, Vol. 12 No. 1: 55 - 65

Budiman, A., 1988. Some aspects on the ecology of mangrove whelk Telecospium Telecospium (Linne, 1758) (Mollusca, Gastropoda: Potamididae). Treubia 29(4):237-245.

Brower, J.E. and J.H. Zar. 1997. Field and Labolatory Menthod for General Ecology. W.M.J. Brown Company Publ.Dubuqe.Lowa.

Dance S.P., 1992. Shells. London : Dorling Kindersley Handbook.

Dharma B., 1988. Siput dan Kerang Indonesia (Indonesian Shells I ). Penerbit : PT. Sarana Graha. Jakarta.

Dharma B., 1992. Siput dan Kerang Indonesia (Indonesian Shells II ). Penerbit : PT. Sarana Graha. Jakarta.

Insafitri. 2010. Keseragaman, dan Dominansi Bivalvia di Area Buangan Lumpur Lapindo Muara Sungai Porong. Jurnal Kelautan. Universitas Trunojoyo. Jurnal kelautan. ISSN 1907-9931

Jansen P., 2000. Seashells Of South-East Australia. Australia : Capricornica Publications.

Masagca, J.T., A.V. Mendoza and E.T. Tribiana. 2010. The Status of Mollusk Diversity and Physical Setting of the Mangrove Zones in Catanduanes Island, Luzon, Philippines. BIOTROPIA Vol. 17 No. 2 : $62-76$

Odum, E.P. 1998. Dasar-Dasar Ekologi.Terjemahan T. Samingan dan B. Srigdanono. Gajah Mada Press. Yogyakarta.

Pravinkumar, M., P. Murugesan, R. K. Prakash, V. Elumalai, C. Viswanathan and S. M. Raffi.2013. Benthic biodiversity in the Pichavaram mangroves, Southeast Coast of India. Journal of Oceanography and Marine Science Vol. 4(1), pp. 1-11

Poutiers J.M., 1998. Gastropods dalam Carpenter, K.A \& V. H. Niem (Ed.). 1998. The Living Marine Resources of Western - Central Pacific. Volume I : Seaweeds, Corals, Bivalves, Gastropods. Roma : FAO of the UN.

Pramudji, 2002. Pengelolaan Kawasan Pesisir dalam Upaya Pengembangan Wisata Bahari. Oseana XXVII, Nomor $1: 27$ - 35. Jakarta.

Rau,A.R., J.D. Kusen dan C.P. Paruntu.2013. Struktur Komunitas Moluska di Vegetasi Mangrove Desa Kulu, Kecamatan Wori, Kabupaten Minahasa Utara. Jurnal Pesisir dan Laut Tropis, Vol.2 No.1: 44-50

Tanjung L., Suwondo, Febrita E., 2012. Kepadatan dan Distribusi Gastropoda pada Mangrove di Pantai Cermin Kecamatan Serdang Bedagai Provinsi Sumatera Utara. Jurnal : Program Studi Pendidikan Biologi Fakultas Keguruan dan Ilmu Pendidikan Universitas Riau. Riau.

Woodward F., 1993. Identifying Shells : The New Compact Study Guide and Identifier. London : Burlington Books. 